\title{
SISTEM AUTOKONEKSI PERANGKAT CERDAS YANG DITERAPKAN PADA SISTEM PENGAWASAN DAN KONTROL DENGAN MENGGUNAKAN INTERNET OF THINGS
}

\author{
Nanda Cahyangtia Pratama ${ }^{1}$, Muhammad Ary Murti ${ }^{2}$, Ratna Mayasari ${ }^{3}$ \\ 1,2,3Fakultas Teknik Elektro, Universitas Telkom \\ 1'npcahyangtia@gmail.com, ${ }^{2}$ arymurti@telkomuniversity.ac.id, ${ }^{3}$ ratnamayasari@telkomuniversity.ac.id
}

\begin{abstract}
Abstrak
Perangkat cerdas yang memiliki kecerdasan dalam melakukan koneksi ke internet dan proses otomatisasi registrasi di server merupakan bagian yang dibutuhkan dalam terbentuknya internet of things. Pada penelitian ini dikembangkan perangkat cerdas untuk membangun sambungan ke internet menggunakan jaringan 3G dengan mendeteksi SIM card yang digunakan dan kecerdasan sistem untuk melakukan otomatisasi registrasi di server, serta mampu mengalokasikan database sesuai dengan ID perangkat cerdas. Penerapan kecerdasan dalam mikrokontroler yaitu kecerdasan dalam memproses data sensor untuk melakukan aksi tertentu. Dari hasil pengujian perangkat, diperoleh waktu yang dibutuhkan untuk mendeteksi SIM card adalah 0,46 detik dan waktu koneksi ke jaringan internet adalah 17,961 detik.
\end{abstract}

Kata Kunci: perangkat cerdas, otomatisasi, registrasi otomatis, deteksi SIM Card, internet of things

\section{Abstract}

Smart device that has smartness in connecting to internet and the automatic registration process on server is required part in formatting the Internet of things. In this research, a smart device was built in connection to the internet using the 3G network data by detecting which SIM card is used and smart systems for the automatic registration on server, and able to allocate the database according to the smart device ID. Smartness application in microcontroller is the smartness in processing the sensor data to perform a particular action. Based on the results of the testing tool, the time needed to detect the SIM card is 0.46 seconds, and to connect the Internet is 17.961 seconds.

Keywords: smart device, automation, automatic registration, detecting SIM Card, Internet of Things

\section{Pendahuluan}

Perkembangan ICT saat ini menuju ke era komunikasi machine to machine, network control system, wireless sensor network dan internet of things yang membuka peluang untuk aplikasi baru dengan menggunakan jaringan data [1], [2], [3]. Internet of Things (IoT) adalah era baru kecerdasan komputasi yang menghubungkan segala benda [4]. IoT juga dapat membentuk komunikasi antar benda dengan orang dan antar benda dengan benda itu sendiri [5]. Sedangkan M2M, merupakan solusi dari internet of things yang menggunakan jaringan nirkabel untuk menghubungkan antar perangkat sehingga meminimalkan campur tangan manusia secara langsung [1]. Internet of things memerlukan beberapa kebutuhan yaitu database yang besar, jaringan yang menghubungkan antar perangkat, kemampuan untuk mendeteksi, dan kepintaran yang tertanam.

Penelitian ini bertujuan untuk membentuk komunikasi antar perangkat dibutuhkan media komunikasi yang handal dan memiliki cakupan yang luas. Mobile Celuller Technology memiliki keuntungan pada cakupan yang luas dan mudah dalam menyediakan koneksi melalui jaringan internet [6]. Dengan cakupan yang luas dalam penerapan dari teknologi internet of things segala sesuatu dapat dipantau dan dikontrol dari jarak yang jauh.

Beberapa penelitian terdahulu membahas tentang system monitoring kondisi rumah menggunakan Xbee S2 [7] untuk menghubungkan antar end device dengan koordinator. Penelitian yang lain juga membahas tentang system monitoring dan kontrol menggunakan Zigbee untuk membangun home automation dengan interface berupa halaman web [5], selain itu ada yang menggunakan SMS untuk mengontrol kondisi rumah dari jauh [8].

Dalam penelitian sebelumnya, untuk menghubungkan ke jaringan seluler hanya dilakukan menggunakan satu operator saja dan jika pengguna ingin menggunakan operator lain, maka perlu melakukan konfigurasi secara manual. Oleh karena itu, dalam penelitian ini dikembangkan kecerdasan perangkat untuk mengidentifikasi kartu SIM, dan konfigurasi akan dilakukan oleh perangkat secara otomatis. Perangkat ini mampu terhubung secara otomatis ke Internet yang disediakan oleh operator manapun. 
Sedangkan dalam penelitian lain, untuk menghubungkan perangkat cerdas ke server dilakukan secara manual dengan memasukkan ID perangkat dan beberapa konfigurasi di sisi server, maka antara client dan server dapat terhubung. Oleh karena itu, sistem pendaftaran otomatis dikembangkan dalam penelitian ini untuk memeriksa $I D$ perangkat di sisi server dan dapat mendaftar $I D$ perangkat yang belum terdaftar sebelumnya. Dengan meningkatkan penelitian ini, perangkat dapat terhubung ke internet dan server secara otomatis tanpa konfigurasi oleh pengguna atau administrator server. Hal ini dapat meminimalkan waktu dalam proses pendaftaran dan lebih user friendly.

Selain itu, diperlukan kecerdasan dalam terbentuknya IoT. Namun dalam penerapannya, kecerdasan dalam mikrokontroler masih terbatas dalam kecerdasan memproses data sensor untuk melakukan aksi tertentu. Perlu adanya penambahan kecerdasan pada mikrokontroler sehingga meningkatkan kehandalan dari perangkat cerdas. Dengan penambahan kecerdasan untuk dapat tersambung dengan jaringan internet merupakan solusi meningkatkan kehandalan dari perangkat cerdas. Menggunakan jaringan $3 \mathrm{G}$ yang disediakan oleh provider di Indonesia, sistem dapat memanfaatkan fasilitas seperti jaringan internet, akses data, dan lain sebagainya. Menambahan teknologi berbasis internet ini memiliki keuntungan pada investasi yang murah dan cakupan yang luas [6]. Selain itu dengan melakukan penambahan kecerdasan pada proses otomatisasi register pada sisi server dapat membantu dalam penyederhanaan proses registrasi.

\section{Desain Sistem}

\subsection{Model Sistem}

Pada Gambar 1 menunjukkan model sistem yang akan dirancang pada penelitian ini. Sistem yang dirancang merupakan penggabungan antara dua proses yaitu proses pengawasan dan kontrol melalui jaringan internet. Secara garis besar penelitian ini terdiri dari tiga bagian yaitu bagian perangkat cerdas, bagian server dan bagian pengguna. Pada bagian perangkat cerdas terdapat beberapa kelebihan yang dimiliki yaitu terdapat kecerdasan untuk terhubung dengan jaringan, pendeteksian keadaan sekitar menggunakan sensor. Pada bagian server terdapat kelebihan untuk melakukan otomatisasi registrasi perangkat cerdas yang terhubung dengan server. Sedangkan, pada bagian pengguna untuk melakukan pengawasan dan kontrol dilakukan menggunakan interface berupa halaman web.

State $\mathrm{S}_{1}=$ Kondisi Tidak Tersambung dengan Jaringan

State $\mathrm{S}_{2}=$ Kondisi Tersambung dengan Jaringan

State $\mathrm{S}_{3}=$ Kondisi Tidak Terhubung dengan Server

State $\mathrm{S}_{4}=$ Kondisi Terhubung dengan Server

State $\mathrm{S}_{5}=$ Kondisi Perintah Tidak Terkirim
State $\mathrm{S}_{6}=$ Kondisi Perintah Terkirim

Pada Gambar 2 menunjukkan alur transisi dari setiap state dalam kecerdasan yang terdapat pada perangkat. Dimulai dari kondisi saat koneksi dengan jaringan, koneksi dengan server selanjutnya kondisi saat perintah dikirimkan.

\subsection{Chart of SIM Card Detection}

Pada Gambar 3 menunjukkan flowchart proses dari deteksi SIM card. Alur pendeteksian dimulai dari pembacaan kode IMSI dari SIM card yang terpasang pada modul 3G menggunakan perintah AT Command. Setelah didapatkan kode IMSI dari SIM card tersebut, kemudian dilakukan perbandingan dengan data yang diinisialisasikan sebelumnya. Jika hasil perbandingan menunjukkan nilai benar maka akan dilanjutkan ke proses pengaturan APN, sedangkan jika hasil perbandingan menunjukkan nilai salah maka perangkat cerdas akan meminta memasukkan SIM card yang sesuai. Setelah proses pengaturan APN selesai maka perangkat cerdas mendapatkan IP yang digunakan untuk tersambung dengan jaringan internet.
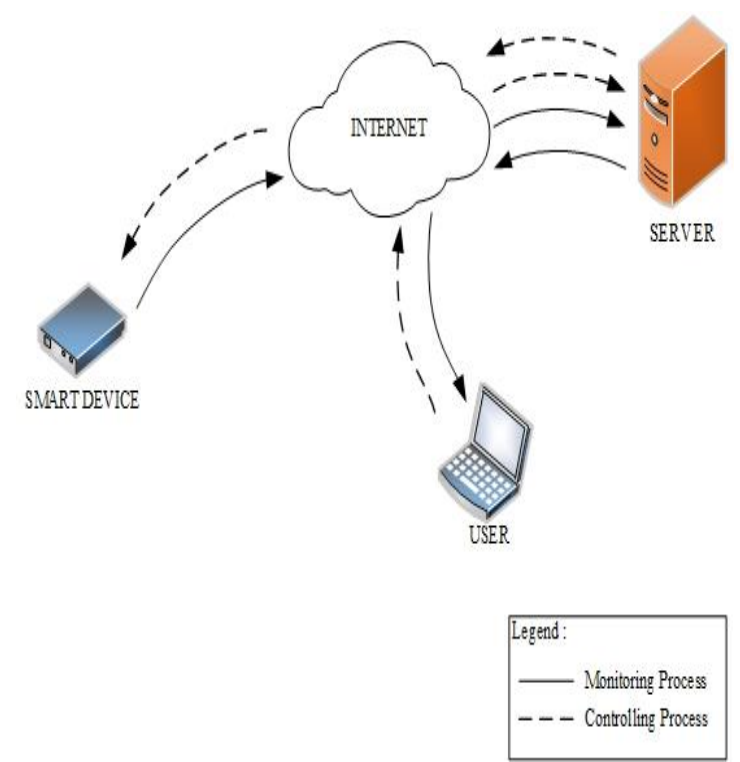

Gambar 1. Model Sistem

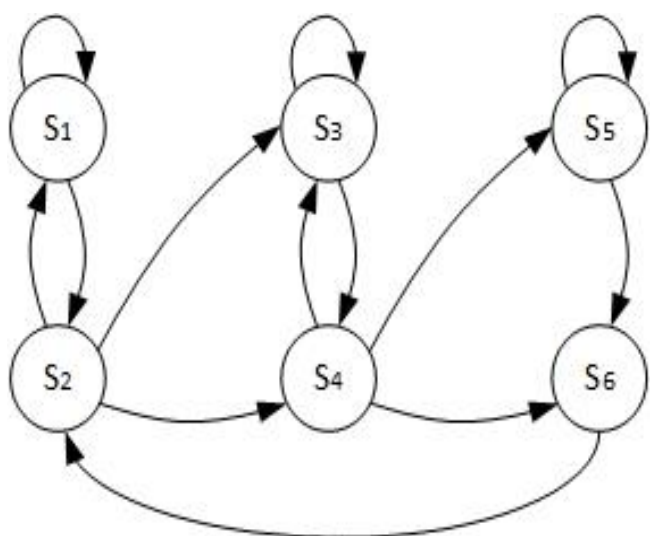

Gambar 2. Rantai Markov Kecerdasan Perangkat 


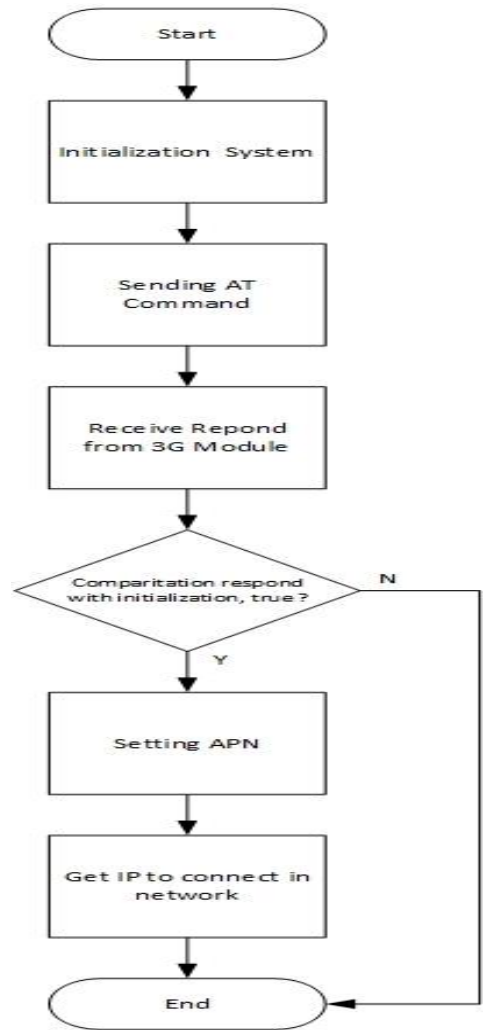

Gambar 3. Flowchart Deteksi SIM Card

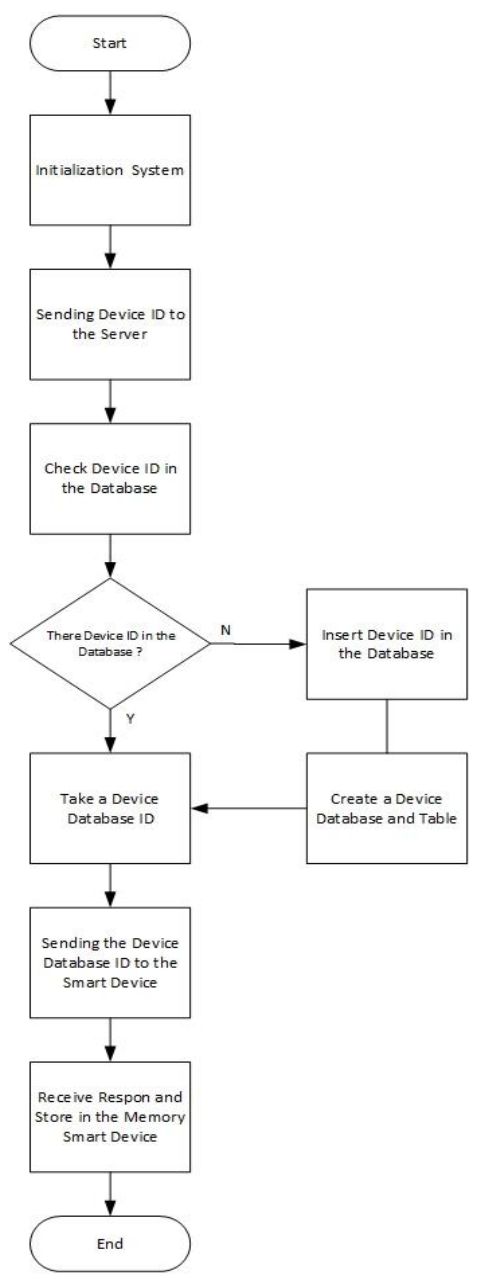

Gambar 4. Flowchart Otomatisasi Registrasi
Tabel 1. Kode IMSI Sistem

\begin{tabular}{|c|c|c|}
\hline Jenis Kode & Kode Unik & Keterangan \\
\hline MCC & 510 & Operator di Indonesia \\
\hline \multirow{3}{*}{ MNC } & 10 & Operator A \\
\cline { 2 - 3 } & 01 & Operator B \\
\cline { 2 - 3 } & 11 & Operator C \\
\hline
\end{tabular}

\subsection{Flowchart Otomatisasi Registrasi}

Pada Gambar 4 menunjukkan flowchart proses otomatisasi registrasi di server. Alur registrasi dimulai dari proses inisialisasi sistem berupa pendeklarasian $I D$ perangkat pada perangkat cerdas, kemudian dilanjutkan proses pengecekanan ID perangkat tersebut ke server untuk diperiksa apakah sudah terdaftar pada database atau belum. Jika $I D$ perangkat tersebut sudah terdaftar maka server akan mengirimkan respon berupa ID dari database yang dialokasikan untuk perangkat tersebut. Namun, jika ID perangkat tersebut belum terdaftar pada database server maka akan dilakukan proses memasukkan $I D$ tersebut dan mengalokasikan database khusus yang digunakan oleh perangkat cerdas untuk menyimpan data. Kemudian server akan mengirimkan respon berupa ID dari database yang dibuat tadi ke perangkat cerdas. Setelah respon diterima oleh perangkat cerdas selanjutnya akan disimpan pada memory perangkat cerdas yang nantinya akan digunakan untuk mengirimkan data dari perangkat cerdas ke server.

\subsection{Flowchart Realisasi Sistem}

Dari Gambar 5 menunjukkan flowchart realisasi sistem yang dimulai dari inisialisasi berupa inisialisasi pada script yang di-upload ke mikrokontroler meliputi inisialisasi kode IMEI provider seluler, inisialisasi port, dan variable pendukung dalam sistem, selain itu juga inisialisasi pada sisi web dan pada shield I/O yang dibuat. Setelah proses inisialisasi selesai, selanjutnya adalah proses pendeteksian SIM card yang digunakan. Jika IMEI dari SIM card yang digunakan terdapat pada inisialisasi, maka proses dilanjutkan pada otomatisasi registrasi di server. Respon dari otomatisasi registrasi yang dikirimkan ke perangkat cerdas berupa $I D$ dari database yang dialokasikan untuk perangkat cerdas tersebut. ID tersebut digunakan untuk proses pengiriman data sensor ke server sehingga data sensor akan masuk pada database yang telah sediakan. Setelah server menerima data dari perangkat cerdas maka data tersebut ditampilkan dalam bentuk grafik pada halaman web. Untuk proses pengontrolan, pada halaman web tersebut terdapat tombol yang telah diprogram sebelumnya untuk memberikan respon ke perangkat cerdas untuk melakukan aksi tertentu. Respon yang dihasilkan dari halaman web tersebut dikirimkan ke server dan menunggu perangkat cerdas melakukan request kontrol untuk mengirimkan respon tersebut ke 
perangkat cerdas. Setelah respon sampai, dilakukan pengolahan data sehingga dapat menyalakan atau mematikan sesuatu di sisi perangkat cerdas.

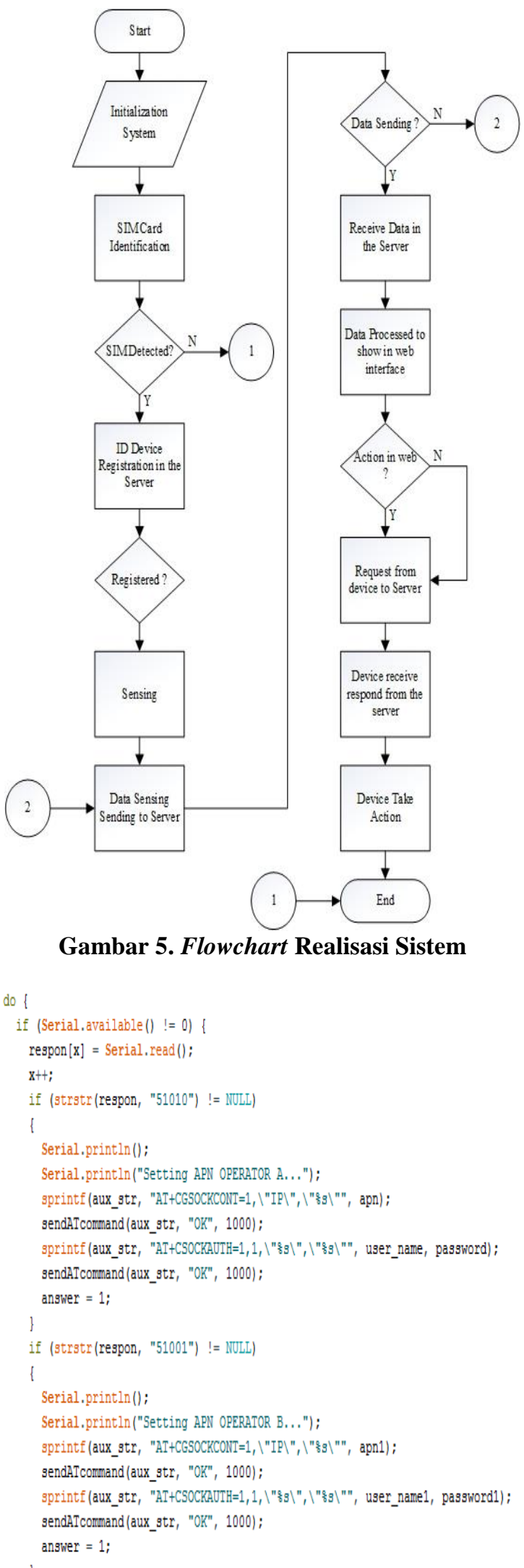

Gambar 6. Potongan Script Perbandingan Kode IMSI

\section{//input}

$\$$ key $=\$ \_$GET['id'];

//proccess main code

\$id_check = "id_device";

\$id_device $=$ "data_table";

lif $($ Check_Id (\$id_check, 'id', \$key $)==$ true $)\{$ echo "OK";

\}else \{

Register_Id(\$id_device, 'id', \$key);

\})

\section{Gambar 7. Potongan Script Otomatisasi Registrasi}

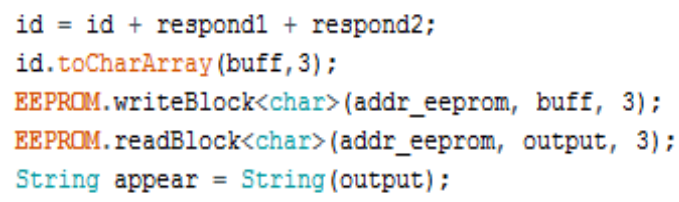

Gambar 8. Potongan Script EEPROM

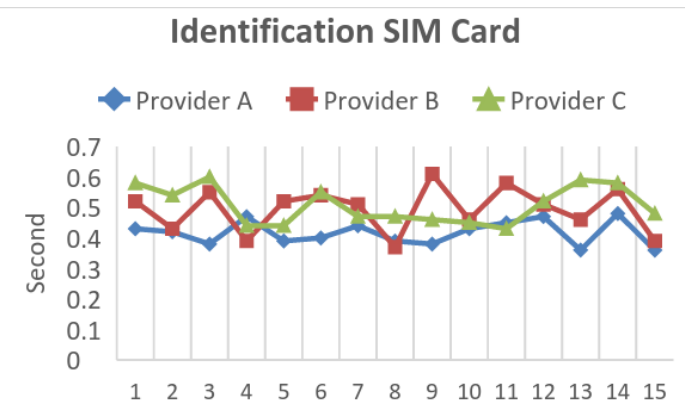

Gambar 9. Identifikasi SIM Card

TIME TO Connected to the internet

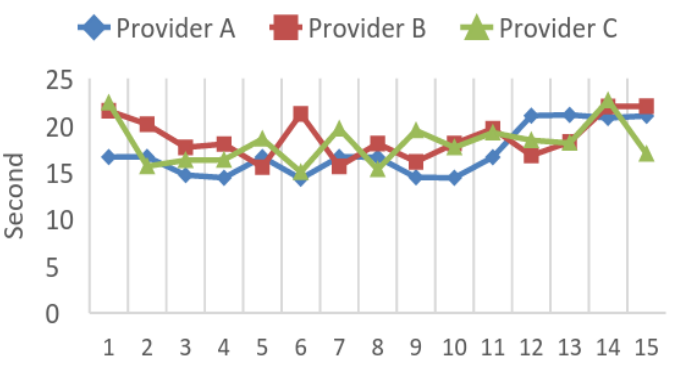

Gambar 10. Waktu Terhubung ke Internet

TIME TO automatic register

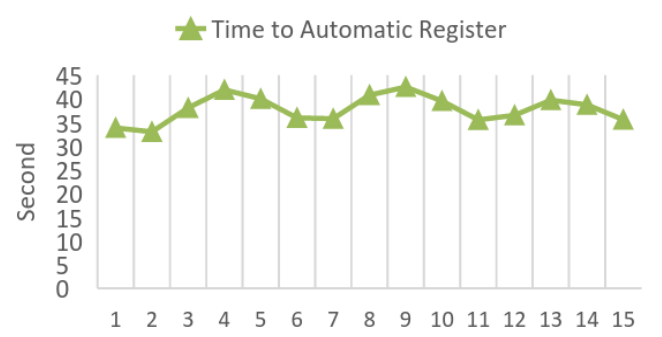

Gambar 11. Waktu Otomatisasi Registrasi 


\section{Implementasi Sistem}

Proses implementasi dari perangkat cerdas yang dibuat menggunakan arduino sebagai mikrokontroler dan modul 3G sebagai interkoneksi dengan jaringan. Implementasi pendeteksian SIM card dilakukan dengan menggunakan perintah AT Command untuk mendapatkan informasi dari modul 3G. Perintah yang digunakan yaitu AT+CIMI untuk mendapatkan informasi berupa kode IMSI SIM card yang digunakan pada modul 3G. IMSI (International Mobile Subsriber Identity) merupakan 15 digit kode unik secara internasional yang terdiri dari kode unik negara, kode jaringan, dan nomer identitas subscriber [9] dimana setiap provider dan setiap subscriber memiliki kode uniknya sendiri. Dari kode IMSI tersebut hanya digunakan lima digit awal yang menandakan identitas negara dan identitas dari provider terkait sehingga bersifat umum dan semua SIM card dari provider tertentu dapat digunakan setelah dideklarasikan lima digit awal kode IMSI. Pada Tabel 1 menunjukkan data kode IMSI yang dipergunakan dalam implementasi pendeteksian SIM card pada penelitian ini.

Proses deteksi IMSI dilakukan dengan membandingkan respon berupa kode IMSI yang didapatkan dari modul $3 \mathrm{G}$ dengan inisialisasi kode IMSI yang menandakan provider terkait yang telah ditanamkan di mikrokontroler untuk menentukan provider yang digunakan. Pada Gambar 5 adalah potongan script perbandingan kode IMSI dari respon modul 3G dengan inisialisasi kode IMSI provider.

Setelah dilakukan proses perbandingan maka didapatkan provider yang digunakan, kemudian modul 3G melakukan pengaturan APN, sehingga modul 3G dapat terkoneksi dengan jaringan internet. APN merupakan mekanisme untuk menentukan MS dalam berkomunikasi melalui jaringan seluler dengan situs lain serta digunakan untuk menentukan alamat $I P$ dari perangkat mobile untuk terhubung dengan GGSN [10].

Implementasi perangkat cerdas yang kedua, yaitu penerapan otomatisasi registrasi. Tahap ini dilakukan dengan membuat beberapa script pada server untuk memeriksa ID perangkat yang dikirimkan perangkat cerdas apakah sudah terdaftar atau belum ketika awal dinyalakan. Kemudian mengirimkan data database yang dialokasikan khusus ke perangkat cerdas ke mikrokontroler untuk disimpan pada memory-nya (EEPROM) untuk proses pengiriman data sensor ke server. Jika $I D$ belum terdaftar maka $I D$ perangkat tersebut disimpan pada database utama dan men-generate database dan tabel yang digunakan untuk menyimpan data dari perangkat cerdas.

Gambar 7 adalah potongan script otomatisasi registrasi di server sedangkan Gambar 8 merupakan potongan script untuk menyimpan data ke memory EEPROM mikrokontroler.

Pada implementasi kecerdasan otomatisasi register, performasi dari sistem dipengaruhi dari proses request data ke sisi server yang dilakukan oleh perangkat cerdas, dimana standart kualitas dan keadaan modul 3G dalam kondisi baik. Diatakan pada kondisi baik jika mendapatkan RSSI pada rentang -50 sampai $-90 \mathrm{dBm}$ menandakan bahwa daya terima mencapai tingkat high signal sampai medium signal dan kualitas jaringan buruk (RSSI pada rentang -91 sampai $-120 \mathrm{dBm}$ low signal sampai poor signal) [11].

\section{Pengukuran dan Analisis}

Pada penelitian ini sistem diukur pada dua hal yaitu, kecepatan dan ketepatan perangkat untuk dapat terhubung dengan jaringan internet serta kecepatan dalam proses otomatisasi registrasi di server. Pengukuran ini dilakukan sebanyak 15 kali percobaan untuk melihat keandalan dari sistem yang dibuat.

\subsection{Kecepatan dan Ketepatan Perangkat untuk dapat Terhubung dengan Internet}

Pada pengukuran ini dilihat berapa waktu yang dibutuhkan perangkat cerdas untuk dapat terhubung dengan jaringan meliputi didalamnya proses pendeteksian SIM card yang digunakan. Skenario pengukuran yang dilakukan yaitu perangkat cerdas menggunakan tiga SIM card yang digunakan secara bergantian. Hasil pengukuran pendeteksian SIM card terdapat pada Gambar 9.

Dari hasil pengukuran sebanyak 15 kali percobaan dapat dilihat bahwa pada perangkat cerdas memiliki kecepatan rata - rata mendeteksi SIM card A selama 0,42 detik serta menghasilkan rata - rata waktu untuk terkoneksi dengan jaringan selama 17,064 detik, sedangkan kecepatan rata - rata mendeteksi SIM card B selama 0,49 detik serta menghasilkan rata - rata waktu selama 18,711 detik dan memiliki kecepatan rata - rata mendeteksi SIM card $\mathrm{C}$ selama 0,51 detik serta menghasilkan rata rata waktu selama 18,108 detik. Dapat ditarik rata rata perangkat cerdas dapat mendeteksi SIM card selama 0,47 detik. Hasil dari proses pendeteksian SIM card tersebut dipengaruhi dari performansi modul 3G dalam mengesekusi perintah AT Command yang dikirimkan dan mengirimkan respon yang didapatkan ke mikrokontroler. Sedangkan untuk terhubung dengan jaringan internet, dipengaruhi proses registrasi ke jaringan dari modul $3 \mathrm{G}$ dan membaca status dari registrasi tersebut.

\subsection{Kecepatan dalam Proses Otomasi Registrasi}

Pada pengukuran ini dilihat berapa waktu yang dibutuhkan dalam pembentukan database sampai dengan perangkat cerdas menyimpan data tersebut dimemory-nya. Skenario pengukuran yang dilakukan yaitu dengan menggunakan satu SIM card untuk melakukan proses registrasi ke server, serta 
perhitungan waktu pada perangkat cerdas dan server untuk menghitung waktu mulai dan waktu akhir. Hasil pengukuran terdapat pada Gambar 11.

Dari hasil tersebut menunjukkan waktu yang dibutuhkan untuk melakukan proses registrasi yang mencakup pembentukan database dan penyimpanan data di sisi perangkat cerdas membutuhkan waktu kurang lebih 37.84 detik. Hasil tersebut dipengaruhi dari proses request data ke sisi server yang dilakukan oleh modul 3G dan performansi dari modul 3G itu sendiri. Pada proses otomatisasi register ini dilakukan dua proses pengiriman perintah ke server, yaitu proses pengecekan $I D$ perangkat dan proses mengambil data pada database yang teralokasi untuk perangkat tersebut. Pada penelitian ini kualitas sinyal yang diterima modul $3 \mathrm{G}$ berkisar $-90 \mathrm{dBm}$ dimana standart kualitas modul 3G dalam kondisi baik jika mendapatkan RSSI pada rentang -50 sampai $-90 \mathrm{dBm}$ menandakan bahwa daya terima mencapai tingkat high signal sampai medium signal dan kualitas jaringan buruk jika RSSI pada rentang -91 sampai $120 \mathrm{dBm}$ low signal sampai poor signal) [11]. Jadi kualitas sinyal yang diterima oleh modul $3 \mathrm{G}$ masuk ke dalam rentang medium signal namun dengan selisih yang sedikit mendekati poor signal sehingga dengan kualitas yang diterima modul 3G akan berpengaruh pada lamanya suatu perintah dikirimkan ke server dan suatu perintah sampai dari server ke perangkat cerdas selain dari performansi modul 3G itu sendiri. Selain itu dengan semakin baiknya kualitas sinyal yang diterima dapat meminimalkan kegagalan dalam proses pengiriman perintah atau menerima perintah ke atau dari server.

\section{Kesimpulan dan Pengembangan Kedepan}

Penelitian ini mengimplementasikan perangkat cerdas yang memiliki kecerdasan dalam terhubung dengan internet dan kecerdasan dalam proses otomatisasi registrasi di server. Kecerdasan yang tertanam pada mikrokontroler dan modul $3 \mathrm{G}$ untuk mendeteksi SIM card dibutuhkan waktu selama 0,47 detik. Perhitungan deteksi SIM card tersebut dipengaruhi oleh performasi modul $3 \mathrm{G}$ dalam membaca perintah yang diberikan dan mengirimkan respon ke mikrokontroler. Selain itu, kecerdasan sistem untuk melakukan otomatisasi registrasi berupa pendataan $I D$ perangkat dan pembuatan database di server untuk tiap perangkat dibutuhkan waktu selama 37,84 detik pada kualitas sinyal yang diterima pada modul 3G sebesar $-90 \mathrm{dBm}$. Kecerdasan untuk melakukan otomatisasi registrasi erat kaitannya dengan kualitas sinyal yang diterima oleh modul $3 \mathrm{G}$. Semakin baik kualitas sinyal yang diterima oleh modul 3G maka semakin maksimum hasil dari proses yang dilakukan untuk otomatisasi registrasi.

Pada penelitian selanjutnya, dibutuhkan pengembangan pada kecerdasan yang telah dibuat dan menambahkan kecerdasan aplikasi yang terhubung dengan pengguna. Kecerdasan tersebut berupa interface yang cerdas sehingga pengguna dapat menikmati layanan yang diberikan sistem dengan maksimal bisa berupa interface aplikasi mobile, atau berupa web base.

\section{Daftar Pustaka}

[1] GSMA, Understanding the Internet of Thing (IoT), July 2014.

[2] M. A. Murti, H. A. Tjokonegoro, E. Leksono and W. Agung, "Multi-delay multi-dropout model of M2M data network for Networked Control System,," Asia-Pacific Conf. Common. Apcc 2013, vol. 19, pp. 509-513, 2013.

[3] A. Ramaddan, M. A. Murti and L. V. Yovita, "Implementation of Networked Control Systems Using Programmable Controller Based Ethernet Network," pp. 432-437, 2013.

[4] S. D. T. Kelly, N. K. Suryadevara and S. C. Mukhopadhyay, "Towards the Implementation of IoT for environmental condition monitoring in homes," IEEE Sens. J, vol. 13, no. 10, pp. 3846-3853, 2013.

[5] S. Pandikumar and R. S. Vetrivel, "Internet of Thinks Based Architecture of Web and Smart Home Interface Using GSM," Int. j. Innov Res. Sci. Eng. Technol., vol. 3, no. 3, pp. 1721-1727, 2014.

[6] M. Collotta and V. Salerno, "A real-time network based on IEEE 802.5. 4/ZigBee to control home automation environment," int. forum " Modern Inf., 2010.

[7] M. A. Murti, H. A. Tjokronegoro, E. Leksono and W. Agung, "Performance Analysis Of HSPA Tecnology for Network Control System Application," Int. J. Comput. Commun. Eng., vol. 5, no. 3, pp. 165-175, 2016.

[8] A. Kurniawan, R. Munadi and R. Mayasari, "Implementasi dan Analisa Wireless Sensor Untuk Monitoring Suhu, Kelembapan dan Kadar CO2 pada Ruangan," Semin. Nas. Inov. dan Apl. Tekno. di Ind., pp. 1-6, 2016.

[9] S. Steig, A network based IMSI Catcher detection, 2016.

[10] M. Number, M. Date, M. Location and I. Category, "Restricted-Confidential Information IREG GPRS Working Party GSM Assosation," vol. 5, pp. 6-9, September 1999.

[11] A. Fourie, Minimum RSSI needed for $3 \mathrm{G}$ or LTE, 2015. 